\title{
Effects of Insulin and Exercise on Muscle Lipoprotein Lipase Activity in Man and Its Relation to Insulin Action
}

\author{
Bente Kiens, "* Hans Lithell, ${ }^{\mathbf{5}}$ Kari J. Mikines," and Erik A. Richter* \\ *August Krogh Institute, University of Copenhagen, Copenhagen, Denmark; ${ }^{\ddagger}$ Research Department of Human Nutrition, The Royal \\ Veterinary and Agricultural University, Copenhagen, Denmark; ${ }^{\S}$ Department of Geriatrics, Uppsala University, Uppsala, Sweden; \\ and "Department of Medical Physiology B, University of Copenhagen, Copenhagen, Denmark
}

\begin{abstract}
The effects of exercise and a physiological increase in plasma insulin concentration on muscle lipoprotein lipase activity (mLPLA), leg exchange of glucose, and serum lipoprotein levels were investigated in healthy young men. During euglycemic hyperinsulinemia $(n=7)$ at $44 \mathrm{mU} \cdot \operatorname{liter}^{-1}$, m-LPLA in nonexercised muscle decreased from $30 \pm 7.4 \mathrm{mU} \cdot \mathrm{g}^{-1}$ wet weight (w.w.) (mean \pm SE) to $19 \pm 3.3(P<0.05)$. Furthermore, the decrease in $\mathrm{m}$-LPLA correlated closely $(r=0.97, P<0.05)$ with the increase in leg glucose uptake. Moreover, basal $\mathrm{m}$ LPLA correlated with the insulin-induced increase in leg glucose uptake $(r=0.93, P<0.05)$. In the control group $(n=6)$ in which saline was infused in place of insulin and glucose, $m$ LPLA in nonexercised muscle did not change with time. No change in m-LPLA was observed immediately after one-legged knee extension exercise, but $4 \mathrm{~h}$ after exercise m-LPLA was higher $(P<0.05)$ in the exercised thigh $\left(47 \pm 17.8 \mathrm{mU} \cdot \mathrm{g}^{-1}\right.$ w.w.) compared with the contralateral nonexercised thigh $\left(29 \pm 6.3 \mathrm{mU} \cdot \mathrm{g}^{-1} \mathrm{w} . \mathrm{w}\right.$.). This difference was not found $8 \mathrm{~h}$ after exercise. The triacylglycerol content of serum lipoproteins decreased during insulin infusion. It is concluded that in contrast to the effect on adipose tissue, physiological concentrations of insulin decrease m-LPLA in proportion to the effect of insulin on muscle glucose uptake, while muscle contractions cause a local, delayed, and transient increase in m-LPLA. Furthermore, basal m-LPLA is an indicator of muscle insulin sensitivity.
\end{abstract}

\section{Introduction}

Lipolysis of triacylglycerol-rich lipoproteins (chylomicrons and VLDL) is initiated by the action of lipoprotein lipase (LPL). ${ }^{1}$ This enzyme is found at the capillary endothelium of several tissues, such as adipose tissue, skeletal muscle, and heart. Studies have suggested that insulin stimulates adipose tissue LPL activity (LPLA) in humans (1) in a dose-dependent

Address correspondence to Dr. Bente Kiens, Research Department of Human Nutrition, The Royal Veterinary and Agricultural University, Rolighedsvej 25, DK-1958 Frederiksberg C, Denmark.

Received for publication 25 October 1988 and in revised form 8 June 1989.

1. Abbreviations used in this paper: d.w., dry weight; LPL, lipoprotein lipase; LPLA, LPL activity; m-LPLA, muscle LPLA; w.w., wet weight.

J. Clin. Invest.

(c) The American Society for Clinical Investigation, Inc. $0021-9738 / 89 / 10 / 1124 / 06 \$ 2.00$

Volume 84, October 1989, 1124-1129 manner (2). On the other hand, recent findings suggest that increased plasma insulin concentrations downregulate LPLA in human skeletal muscle. Thus, $3 \mathrm{~d}$ on a carbohydrate-rich diet (80 energy \%) was associated with high plasma insulin concentrations and 55\% lower LPLA in human skeletal muscle than seen on an ordinary control diet (3). Furthermore, after a diet poor in carbohydrates, which were primarily derived from fiber-rich products, plasma insulin and glucose values were much lower and muscle LPLA (m-LPLA) higher than when diets with large proportions of simple carbohydrates were consumed (4). On the basis of these data it might be suggested that m-LPLA is sensitive to variation in plasma insulin concentrations. Circulating hormones may be involved in the regulation of m-LPLA, but substrate availability may also influence m-LPLA. Thus, m-LPLA was higher in the morning after heavy work than in the morning after rest (5).

Recently it has been proposed that insulin activation of a phospholipase $\mathrm{C}$ leads to production of diacylglycerol and an inositol phosphate glycan (6), both of which may elicit some of insulin's effects (6-8). In addition, evidence has been presented that insulin-induced activation of phospholipase $\mathrm{C}$ may cleave the glycosyl phosphoinositol anchor of LPL and thereby cause release of LPL from 3T3-L1 cells (9). Therefore, possible insulin effects on LPLA in tissue may covariate with insulin effects on metabolism, and this possibility was also explored in the present study.

To obtain more detailed information on how m-LPLA is regulated by exercise and insulin, and to explore possible relationships between insulin action on glucose uptake and LPLA, we have studied a well-defined muscle group in man in which substrate utilization can be quantified and from which biopsies can be obtained. To be able to conduct studies during steadystate hyperinsulinemia the euglycemic hyperinsulinemic clamp procedure was used.

\section{Methods}

\section{Subjects}

Eight healthy male subjects (mean age 22 yr) gave their informed consent to participate in the study which was approved by the Copenhagen Ethics Committee. Body weight and height averaged $72.6 \mathrm{~kg}$ $(55.8-83.1)$ and $184 \mathrm{~cm}(180-186 \mathrm{~cm})$, respectively. Maximal oxygen consumption determined on a Krogh bicycle ergometer was 52 $\mathrm{ml} \cdot \mathrm{kg}^{-1} \cdot \mathrm{min}^{-1}(48-60)$. None participated in competitive sports, but three participated in leisure time physical activity 1-2 times a week and all subjects used the bicycle for local transportation. Subjects were assigned to either a group that received intravenous insulin and glucose (clamp group, $n=7$ ) or a control group that received an infusion of $0.9 \%$ saline $(n=6)$. Five of the subjects participated in both groups. The subjects were instructed to abstain from strenuous physical activity for $5 \mathrm{~d}$ before the study and to eat a carbohydrate-rich diet for the last $3 \mathrm{~d}$ before the study to ensure filled muscle glycogen stores. 


\section{Protocol}

The subjects arrived in the laboratory in the morning after a 10-12-h overnight fast. Subjects performed $60 \mathrm{~min}$ of repeated, dynamic knee extensions with one leg at $75 \%$ of their maximum one-legged knee extensor work capacity determined previously. With this exercise model work is performed exclusively by the quadriceps femoris muscle (10).

Clamp group. In the clamp study Teflon catheters were then inserted below the inquinal ligament, in one femoral artery (Seldinger technique), and in both femoral veins. The catheters were advanced proximally so that the tips of the arterial and venous catheters were located $\sim 2 \mathrm{~cm}$ proximal and $2 \mathrm{~cm}$ distal to the inquinal ligament, respectively. For measuring of thigh blood flow a thermistor (Edslab probe 94-030-2.5 F; American Edwards Laboratory, Irvine, CA) was inserted through each venous catheter and advanced $6-8 \mathrm{~cm}$ proximal to the catheter tip. Blood flow was measured by the thermodilution technique (11) modified for resting conditions (12). During blood drawing and blood flow measurements a pneumatic cuff right below the knee was inflated to $230 \mathrm{mmHg}$.

Additional catheters were placed in an antecubital vein for glucose and insulin infusion as well as in a dorsal hand vein. After insertion of the catheters the subjects rested in the supine position for $\sim 2 \mathrm{~h}$ until 4 $h$ had elapsed since the termination of exercise. Then preinfusion baseline blood samples were drawn simultaneously from the femoral artery and vein and femoral venous blood flow was measured in both thighs. Subsequently a needle biopsy was obtained from the vastus lateralis muscle of both legs. A two-step sequential euglycemic glucose-insulin clamp procedure (13) was then initiated. Sequential infusion of insulin at primed constant rates of 0.3 and 0.7 $\mathrm{mU} \cdot \mathrm{kg}^{-1} \cdot \mathrm{min}^{-1}$, respectively, was administered in six subjects, each for $110 \mathrm{~min}$, resulting in average steady-state plasma insulin concentrations of 23 and $40 \mathrm{mU} \cdot$ liter $^{-1}$, respectively. In the seventh subject the insulin infusion rates were 0.4 and $1.1 \mathrm{mU} \cdot \mathrm{kg}^{-1} \cdot \mathrm{min}^{-1}$, respectively, resulting in steady-state plasma insulin concentrations of 24 and $69 \mathrm{mU} \cdot \operatorname{liter}^{-1}$, respectively. Average plasma insulin levels for all seven subjects were 23 and $44 \mathrm{mU} \cdot \operatorname{liter}^{-1}$, respectively, for the two clamp steps. Based on measurements of arterialized plasma glucose concentrations obtained through the heated hand vein catheter every $5 \mathrm{~min}$, glucose infusion rate was adjusted to maintain euglycemia.

Before each clamp step 30 meq potassium (Kalinorm; Alfred Benzon, Copenhagen), as slowly released $\mathrm{KCl}$, was administered orally to maintain normokalemia. After $100 \mathrm{~min}$ of insulin infusion at each step, blood was drawn twice for analysis of blood metabolites and hormones and thigh venous blood flow was measured as in the basal state. After the highest clamp step, blood was also drawn for analysis of lipoproteins as at baseline, and another muscle biopsy was obtained from each thigh.

Control group. A muscle biopsy from each vastus lateralis muscle was obtained before and immediately after one-legged knee extensions. Then a catheter was inserted in a retrograde direction in a dorsal hand vein $4 \mathrm{~h}$ after exercise. The hand was placed in a heating pad and arterialized blood (oxygen saturation 94-96\%) was drawn from the heated hand vein. Then a muscle biopsy was obtained from both thighs. Arterialized blood was drawn again after 2 and 4 more $h$, and a muscle biopsy was obtained from both thighs after $4 \mathrm{~h}$. During the last $4 \mathrm{~h}$ of recovery the control group received saline infusion through a catheter in an antecubital vein instead of glucose and insulin, which were given in the clamp group. Saline was given in equal amounts to glucose and insulin.

\section{Blood analysis}

Lipoproteins were separated by ultracentrifugation. A detailed description of the procedures for analyzing lipoproteins has been published previously (14). To minimize any transfer of lipids from VLDL and LDL to HDL during the preparative ultracentrifugation the following procedure was applied. $\mathrm{A} \mathrm{MgCl}_{2}$ phosphotungstate technique was used to precipitate the VLDL and LDL. The supernatant was ultracentrifuged (model LKB-65; Beckman Instruments, Inc., Palo Alto, CA) at a density of 1.125 to separate $\mathrm{HDL}_{2}$ and $\mathrm{HDL}_{3}$.

VLDL in serum were isolated in the top fraction in a separate ultracentrifugation run at a density of 1.006 . LDL were precipitated with $\mathrm{MgCl}_{2}$ phosphotungstate from the bottom fraction after the ultracentrifugation step and HDL were isolated in the supernatant after the precipitation. Triacylglycerol and cholesterol concentrations were assayed in serum and in the different isolated lipoprotein subclasses using enzymatic methods (Boehringer Mannheim GmbH, Mannheim, FRG) in a Multistat III (Instrumentation Laboratory, Inc., Lexington, MA). The triacylglycerol method is based on assay of glycerol after hydrolysis of the triacylglycerols.

The HDL subclasses $\mathrm{HDL}_{2}$ and $\mathrm{HDL}_{3}$ (see above) were assayed in quadruplicate and the mean values used in the calculations. The analytical error (coefficient of variation) was 1.3 and $1.4 \%$ for triacylglycerol and cholesterol analyses, respectively. For HDL cholesterol the coefficient of variation was $5.8 \%$, including the precipitation step.

Glucose in blood and plasma was determined by the fixed glucose oxidase method using a glucose analyzer (Yellow Springs Instrument Co., Yellow Springs, OH). FFA in plasma were determined fluorometrically by a modification of the method of Shimizu et al. (15) as described by Kiens (16). $\beta$-Hydroxybuturate and glycerol in blood were analyzed in accordance with Bergmeyer (17) adjusted to fluorometric assays. Insulin in plasma was determined using a commercially available RIA kit kindly donated by Novo (Copenhagen, Denmark). Catecholamines in plasma were determined by a radioenzymatic procedure (18). Hemoglobin was measured in blood with an OSM II hemoximeter (Radiometer, Copenhagen, Denmark). Lipoproteins were corrected for hemodilution by means of hemoglobin concentrations.

\section{Muscle biopsy analyses}

LPLA in muscle was measured as described by Lithell and Boberg (19) with slight modifications (20). The tissue (10-15 mg) was incubated in a heparin-containing (140 IU heparin $\cdot \operatorname{liter}^{-1}$ ) medium with a serumactivated triolein emulsion (triglyceride concentration, 5.7 mmol $\cdot$ liter $^{-1}$ ) with $\left[{ }^{3} \mathrm{H}\right]$ trioleate as trace substance (21) and albumin $\left(7.5 \mathrm{mg} \cdot \mathrm{ml}^{-1}\right)$ as acceptor of released fatty acids. The linear phase of release of $\left[{ }^{3} \mathrm{H}\right]$ oleic acid was measured during the last $60 \mathrm{~min}$ of a 110-min incubation and the release was used as a measure of LPLA. 1 nmol of the fatty acid released per min was equal to $1 \mathrm{mU}$ of enzyme activity and the activity is expressed per gram wet weight (w.w.). Muscle glycogen (22) and citrate synthase activities (23) were assayed on freeze-dried muscle dissected free of adipose tissue, connective tissue, and blood using a fluorometrical technique.

Statistical evaluations. Nonparametric paired Wilcoxon ranking test and linear regression analysis were used for statistical analysis. The level of significance was set at 0.05 .

\section{Results}

Clamp group. Before insulin infusion m-LPLA in the clamp group averaged $30 \mathrm{mU} \cdot \mathrm{g}^{-1} \mathrm{w} . \mathrm{w}$. in the nonexercised leg and $40 \mathrm{mU} \cdot \mathrm{g}^{-1} \mathrm{w} . \mathrm{w}$. in the exercised leg $(P<0.05$; Fig. 1$)$. At the end of the second clamp step the m-LPLA decreased ( $P$ $<0.05)$ to 19 and $33 \mathrm{mU} \cdot \mathrm{g}^{-1} \mathrm{w} . \mathrm{w}$. in the nonexercised and exercised leg, respectively (Fig. 1). Before insulin infusion the muscle glycogen concentration was 540 and $335 \mu \mathrm{mol} \cdot \mathrm{g}^{-1} \mathrm{dry}$ weight (d.w.) in the nonexercised and exercised thigh, respectively $(P<0.05)$, and at the end of the second clamp step the glycogen concentrations were 525 and $370 \mu \mathrm{mol} \cdot \mathrm{g}^{-1} \mathrm{~d}$.w., respectively (Fig. 2). The increase in the exercised thigh was significant $(P<0.05)$. In the nonexercised thigh glucose uptake, calculated from arterial-venous concentration differences in blood and the blood flow, averaged $0.79 \pm 0.21 \mathrm{mg} \cdot \mathrm{kg}^{-1}$ thigh $\cdot \min ^{-1}$ before insulin infusion and increased to 


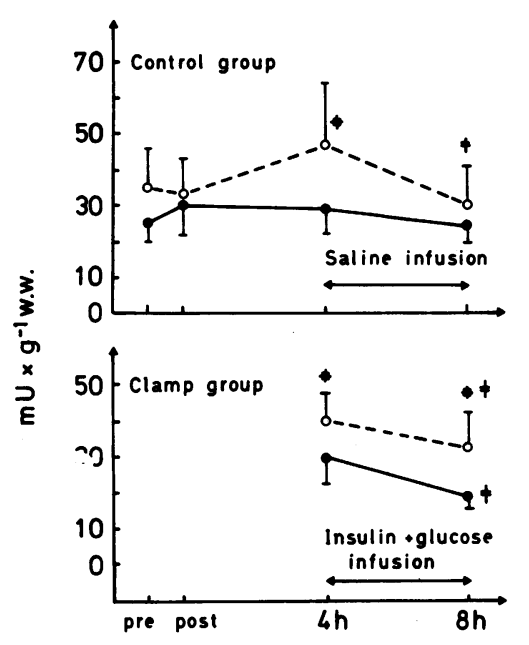

Figure 1. m-LPLA in the nonexercised ( $\bullet$ ) and exercised (o) thigh in the control (top) and clamp groups (bottom). In the clamp group the steady-state plasma insulin concentrations were 23 and 44 $\mathrm{mU} \cdot$ liter $^{-1}$ at 6 and $8 \mathrm{~h}$ of recovery, respectively. In the control group, LPLA was measured before (pre) and after (post) one-legged knee extensions as well as during recovery for 4 and 8 h. ${ }^{*} P<0.05$ compared with contralateral thigh. ${ }^{\ddagger} P<0.05$ compared with previous measurement.

$7.60 \pm 1.22 \mathrm{mg} \cdot \mathrm{kg}^{-1}$ thigh $\cdot \mathrm{min}^{-1}$ during the second clamp step. The decrease in m-LPLA correlated significantly with the increase in thigh glucose uptake $(r=0.97, P<0.05$; Fig. 3) and the basal m-LPLA correlated with the increase in thigh glucose uptake ( $r=0.93, P<0.05$; Fig. 4). In the exercised thigh glucose uptake was $1.41 \pm 0.21$ before insulin infusion and increased to $10.8 \pm 1.1 \mathrm{mg} \cdot \mathrm{kg}^{-1}$ thigh $\cdot \mathrm{min}^{-1}$ during the second clamp step. In the exercised thigh no significant correlation was found between the decrease in m-LPLA and the increase in glucose uptake.

The activity of citrate synthase in muscle was measured in all clamp group subjects and was $41.3 \pm 2.1 \mu \mathrm{mol} \cdot \mathrm{g}^{-1} \cdot \mathrm{min}^{-1}$ d.w. (mean \pm SE).

Control group. Preexercise m-LPLA averaged 25 and 35 $\mathrm{mU} \cdot \mathrm{g}^{-1}$ w.w. in the nonexercised and exercised thighs, respectively (Fig. 1). The difference was not significant. Immediately after exercise m-LPLA was similar in the nonexercised (33 $\mathrm{mU} \cdot \mathrm{g}^{-1}$ w.w.) and exercised $\left(30 \mathrm{mU} \cdot \mathrm{g}^{-1}\right.$ w.w.) thighs (Fig. 1). However, after $4 \mathrm{~h}$ of recovery m-LPLA was significantly

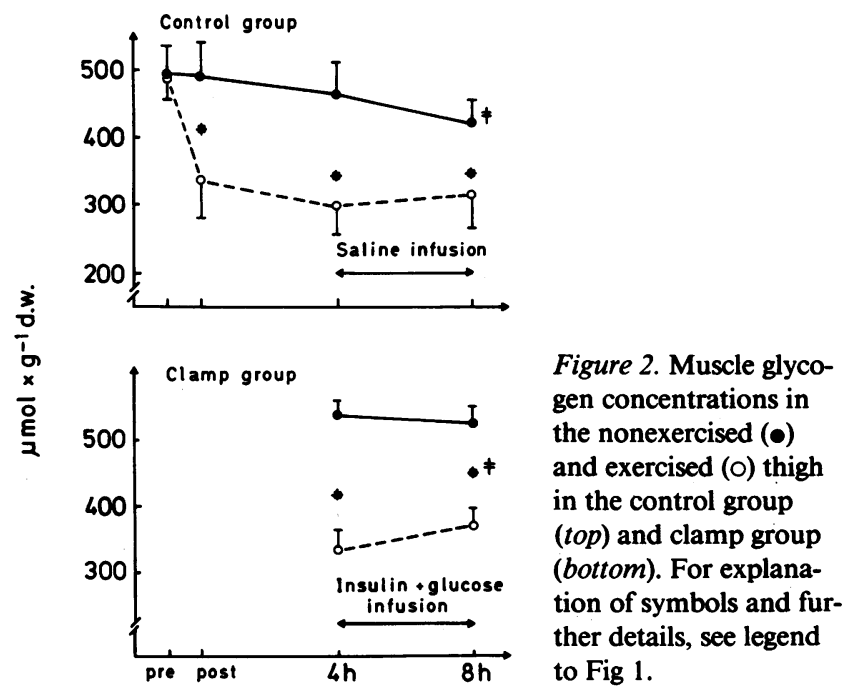

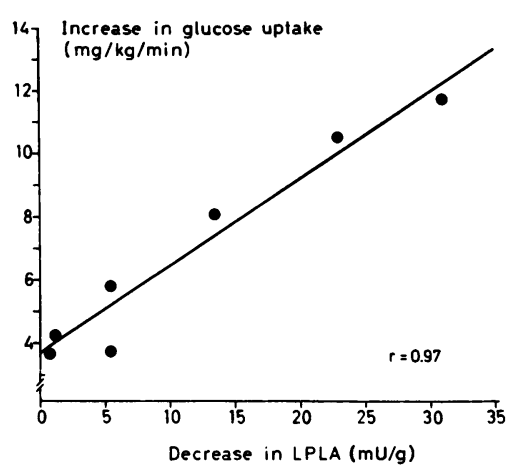

Figure 3. The relationship between increase in glucose uptake (milligrams $\cdot$ kilogram $^{-1}$. minute $\left.^{-1}\right)$ and decrease in $\mathrm{m}$-LPLA (milliunits $\left.\cdot \mathrm{gram}^{-1}\right)$ after insulin infusion at the second clamp step (44 $\mathrm{mU} \cdot$ liter $^{-1} ; r=0.97, P$ $<0.05$ ).

higher $\left(47 \mathrm{mU} \cdot \mathrm{g}^{-1}\right.$ w.w.) in the exercised muscle than in the nonexercised muscle $\left(29 \mathrm{mU} \cdot \mathrm{g}^{-1}\right.$ w.w.; Fig. 1). After $8 \mathrm{~h}$ of recovery the activity of LPL had decreased significantly in the exercised thigh to $29 \mathrm{mU} \cdot \mathrm{g}^{-1}$ w.w., whereas it remained unchanged $\left(24 \mathrm{mU} \cdot \mathrm{g}^{-1} \mathrm{w} . \mathrm{w}\right.$.) in the nonexercised thigh (Fig. 1). Muscle glycogen was similar in the two thighs before exercise, decreased in the exercised muscle during exercise, and did not increase in the recovery period (Fig. 2). In the nonexercised thigh, muscle glycogen concentrations decreased slightly but significantly throughout the recovery period (Fig. 2).

Blood variables. During insulin infusion arterial FFA concentrations decreased dramatically $(\sim 90 \%)$. In contrast to the marked decrease in arterial FFA concentrations, insulin infusion decreased arterial glycerol concentrations by only $30-40 \%$ (Table I). The control group, however, demonstrated a rise in both FFA and glycerol during the saline infusion (Table II).

Serum triacylglycerol decreased significantly during insulin infusion from $1.08 \pm 0.15$ to $0.67 \pm 0.10 \mathrm{mmol} \cdot \mathrm{liter}^{-1}$, whereas it did not change in the control group (from $1.07 \pm 0.20$ to $1.08 \pm 0.19 \mathrm{mmol} \cdot$ liter $\left.^{-1}\right)$. The insulin-induced decrease in serum triacylglycerol was reflected in decreases in the lipoprotein subfractions: VLDL-triacylglycerol decreased from $0.58 \pm 0.11$ to $0.33 \pm 0.09 \mathrm{mmol} \cdot \operatorname{liter}^{-1}(P<0.05)$, LDL-triacylglycerol from $0.28 \pm 0.03$ to $0.25 \pm 0.02 \mathrm{mmol}^{\circ} \operatorname{liter}^{-1}$, and HDL-triacylglycerol from $0.21 \pm 0.06$ to $0.08 \pm 0.01$ $\mathrm{mmol} \cdot \operatorname{liter}^{-1}(P<0.05)$. Serum cholesterol decreased slightly but significantly with insulin infusion from $4.08 \pm 0.19$ to $3.91 \pm 0.17 \mathrm{mmol} \cdot \mathrm{liter}^{-1}$. This was due to a decrease in $\mathrm{HDL}_{2}-$ cholesterol (Table III), whereas $\mathrm{HDL}_{3}$-cholesterol and LDLcholesterol remained unchanged (Table III). In the control group serum cholesterol did not change significantly (from $4.19 \pm 0.24$ to $4.11 \pm 0.24 \mathrm{mmol} \cdot$ liter $^{-1}$ ), nor did the cholesterol content of the lipoprotein subfractions (Table III).

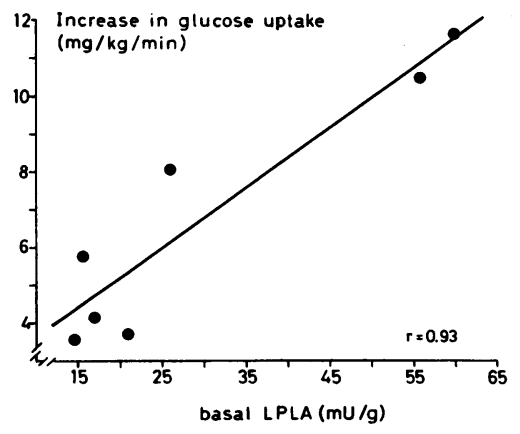

Figure 4. The relationship between increase in thigh glucose uptake $\left(\mathrm{mg} \cdot \mathrm{kg}^{-1} \cdot \mathrm{min}^{-1}\right)$ after insulin infusion at the second clamp step ( 44 $\left.\mathrm{mU} \cdot \mathrm{liter}^{-1}\right)$ and preinfusion $\mathrm{m}$-LPLA $\left(\mathrm{mU} \cdot \mathrm{g}^{-1} ; r=0.93, P\right.$ $<0.05)$. 
Table I. Arterial Concentrations of Metabolites and Hormones in the Clamp Group

\begin{tabular}{|c|c|c|c|}
\hline Clamp step & Preinfusion & I & II \\
\hline Glucose* $\left(\mathrm{mmol} \cdot\right.$ liter $\left.^{-1}\right)$ & $4.68 \pm 0.07$ & $4.82 \pm 0.08$ & $4.91 \pm 0.11$ \\
\hline FFA $\left(\mu \mathrm{mol} \cdot\right.$ liter $\left.^{-1}\right)$ & $346 \pm 40$ & $82 \pm 18^{\ddagger}$ & $55 \pm 15^{\ddagger}$ \\
\hline Glycerol* $^{*}\left(\mu \mathrm{mol} \cdot\right.$ liter $\left.^{-l}\right)$ & $42 \pm 2.0$ & $29 \pm 2.0^{\ddagger}$ & $24 \pm 2.6^{\ddagger}$ \\
\hline \multicolumn{4}{|l|}{$\beta$-OH-butyrate* } \\
\hline$\left(\mu \mathrm{mol} \cdot\right.$ liter $\left.^{-l}\right)$ & $56 \pm 23$ & $6.6 \pm 0.9^{\ddagger}$ & $4.9 \pm 0.7^{\ddagger}$ \\
\hline Insulin $\left(m U \cdot\right.$ liter $\left.^{-1}\right)$ & $7.0 \pm 0.5$ & $23 \pm 1$ & $44 \pm 4$ \\
\hline Epinephrine $\left(n g \cdot m l^{-l}\right)$ & $0.11 \pm 0.01$ & $0.13 \pm 0.03$ & $0.19 \pm 0.05^{\ddagger}$ \\
\hline Norepinephrine $\left(n g \cdot m l^{-l}\right)$ & $0.30 \pm 0.05$ & $0.32 \pm 0.06$ & $0.35 \pm 0.05$ \\
\hline
\end{tabular}

Values (mean $\pm \mathrm{SE}, n=7$, except for catecholamines where $n=6$ ) were obtained before insulin infusion and after $110 \mathrm{~min}$ of euglycemic hyperinsulinemia of 23 (I) and 44 (II) $\mathrm{mU} \cdot \operatorname{liter}^{-1}$, respectively.

* Values are measured in blood; the remaining values are measured in plasma.

${ }^{\ddagger} P<0.05$ compared with basal values.

\section{Discussion}

Nonexercised thigh. The present study shows that LPLA in human skeletal muscle is decreased during an infusion of insulin resulting in a physiological plasma concentration (44 $\mathrm{mU} \cdot$ liter $^{-1}$ ). This finding confirms previous findings that elevated plasma insulin concentrations were associated with lower m-LPLA (4). The effect of insulin could be either direct or indirect, elicited by insulin-induced changes in muscle metabolism. The present study revealed a close correlation between insulin-induced thigh glucose uptake and the decrease in LPLA in muscle ( $r=0.97$; Fig. 3). This relationship may suggest that the effect of insulin on m-LPLA is secondary to changes in muscle metabolism (e.g., the increase in glucose metabolism). The concept that changes in glucose metabolism may influence LPLA is in accordance with recent findings in cultured human adipocytes where physiological glucose concentrations increased LPLA compared with adipocytes grown in a glucose-free medium (24). It is interesting to note that glucose apparently has opposite effects on LPLA in muscle and adipose tissue. The mechanism behind these opposite effects remain to be elucidated.

Table II. Concentrations in Arterialized Blood of Metabolites and Hormones in the Control Group

\begin{tabular}{lccc}
\hline & $4 \mathrm{~h}$ & $6 \mathrm{~h}$ & $8 \mathrm{~h}$ \\
\hline Glucose $^{*}\left(\mathrm{mmol} \cdot\right.$ liter $\left.^{-1}\right)$ & $4.16 \pm 0.14$ & $4.30 \pm 0.11$ & $4.15 \pm 0.10$ \\
FFA $\left(\mu \mathrm{mol} \cdot\right.$ liter $\left.^{-1}\right)$ & $361 \pm 60$ & $464 \pm 38^{\ddagger}$ & $585 \pm 48^{\S}$ \\
Glycerol* $^{\prime}\left(\mu \mathrm{mol} \cdot\right.$ liter $\left.^{-1}\right)$ & $44 \pm 4.5$ & $60 \pm 2.8^{\ddagger}$ & $65 \pm 1^{\ddagger}$ \\
Insulin $\left(\mathrm{mU} \cdot \mathrm{liter}{ }^{-1}\right)$ & $7.5 \pm 1.1$ & $6.2 \pm 1.0^{\ddagger}$ & $6.5 \pm 1.0^{\ddagger}$ \\
Epinephrine $\left(\mathrm{ng} \cdot \mathrm{ml}^{-1}\right)$ & $0.08 \pm 0.02$ & $0.10 \pm 0.02$ & $0.11 \pm 0.02$ \\
Norepinephrine $\left(\mathrm{ng} \cdot \mathrm{ml}^{-1}\right)$ & $0.25 \pm 0.03$ & $0.21 \pm 0.03$ & $0.19 \pm 0.02$
\end{tabular}

Values were obtained 4, 6, and $8 \mathrm{~h}$ after one-legged knee extensions and are means $\pm \mathrm{SE}$ of six observations.

* Values are measured in blood; the remaining values are measured in plasma.

${ }^{\ddagger} P<0.05$ compared with $4 \mathrm{~h}$.

${ }^{\S} P<0.05$ compared with previous value.
Another interesting aspect of the close correlation between the decrease in LPLA and the increase in glucose uptake pertains to signal transduction. Insulin has been shown to activate a specific phospholipase that hydrolyzes a glycosyl phosphatidylinositol molecule. This in turn generates diacylglycerol and an inositol phosphate glycan (6). Both of these substances may generate insulinlike effects (e.g., increase in glucose uptake; 6-8). However, insulin-induced activation of a specific phospholipase $\mathrm{C}$ also causes release of LPL from 3T3-L1 adipocytes presumably by phospholipase $\mathrm{C}$-induced cleavage of the glycolipid membrane anchor of LPL (9). Thus, if the insulininduced decrease in m-LPLA seen in the present study is a function of phospholipase $C$ activation, then the observed close correlation between the decrease in LPLA and the increase in glucose uptake (Fig. 3 ) is in agreement with the assumption that at least some of the effects of insulin (in this case stimulation of glucose uptake in human muscle) may be mediated through activation of phospholipase $\mathrm{C}$.

The insulin-induced increase in thigh glucose uptake was closely correlated to the basal m-LPLA ( $r=0.93$; Fig. 4). Therefore, since insulin-induced glucose uptake at 44 $\mu \mathrm{U} \cdot \mathrm{ml}^{-1}$ is a measure of insulin sensitivity, m-LPLA in resting muscle covariates with insulin sensitivity. This may be due to a causal link between the two or a common factor influencing both insulin sensitivity and m-LPLA (e.g., capillary density; 25, 26).

Exercised thigh. In the clamp group as well as the control group m-LPLA was significantly higher in the exercised muscle than in the nonexercised muscle $4 \mathrm{~h}$ after exercise (Fig. 1). This indicates that muscle contractions cause a local and delayed increase in m-LPLA, since the increase was not apparent immediately after exercise (Fig. 1). A lack of increase in $\mathrm{m}$ LPLA immediately after exercise is in accordance with previous studies using one-legged knee extension exercise for $2 \mathrm{~h}$ (26), as well as bicycle exercise (27). Also of interest is the finding that the increase was transient, since it was no longer apparent $8 \mathrm{~h}$ after exercise (Fig. 1). The biphasic contractioninduced response of m-LPLA was apparently not related to changes in muscle glycogen concentrations, since these were decreased at the end of exercise and did not change in the recovery period (Fig. 2).

In contrast to the findings in the nonexercised leg, the decrease in m-LPLA in the exercised muscle during insulin infusion did not correlate with the increase in thigh glucose uptake. However, it should be noted that the decrease in m-LPLA in the exercised leg from 4 to $8 \mathrm{~h}$ recovery was of similar magnitude in the clamp group and the control group (Fig. 1), which indicates that m-LPLA was uninfluenced by insulin in the exercised thigh. In other words, whereas insulin decreases $\mathrm{m}$ LPLA in nonexercised muscle, it is probably counteracted by some other mechanism and is apparently without effect in exercised muscle. In this light the lack of correlation between the decrease in m-LPLA and the increase in thigh glucose uptake during insulin infusion in the exercised thigh is not surprising.

Blood variables. Insulin infusion was accompanied by a marked decrease in serum triacylglycerol, and this decrease was reflected in decreases in the triacylglycerol content of all lipoprotein subfractions. When insulin was administered to human subjects by the euglycemic clamp technique, plasma triacylglycerols decreased rapidly before changes in activity of 
Table III. Cholesterol Content of Lipoproteins in the Femoral Artery (A) in the Clamp Group and from a Heated Hand Vein $\left(H_{v}\right)$ in the Control Group (Millimoles $\cdot$ Liter $^{-1}$ )

\begin{tabular}{|c|c|c|c|c|c|c|c|c|c|c|}
\hline & \multicolumn{2}{|c|}{ VLDL-cholesterol } & \multicolumn{2}{|c|}{ LDL-cholesterol } & \multicolumn{2}{|c|}{ HDL-cholesterol } & \multicolumn{2}{|c|}{$\mathrm{HDL}_{2}$-cholesterol } & \multicolumn{2}{|c|}{$\mathrm{HDL}_{3}$-cholesterol } \\
\hline & A & $\mathrm{H}_{\mathrm{v}}$ & A & $\mathrm{H}_{\mathrm{v}}$ & A & $\mathrm{H}_{\mathrm{v}}$ & A & $\mathrm{H}_{\mathrm{v}}$ & A & $\mathrm{H}_{\mathrm{v}}$ \\
\hline Basal & $0.29 \pm 0.05$ & $0.31 \pm 0.09$ & $2.81 \pm 0.21$ & $2.87 \pm 0.23$ & $1.03 \pm 0.07$ & $0.96 \pm 0.10$ & $0.37 \pm 0.06$ & $0.33 \pm 0.08$ & $0.61 \pm 0.02$ & $0.64 \pm 0.04$ \\
\hline Ins $_{\mathrm{II}} /$ saline & $0.24 \pm 0.06$ & $0.30 \pm 0.09$ & $2.81 \pm 0.17$ & $2.87 \pm 0.23$ & $0.94 \pm 0.06$ & $0.95 \pm 0.10$ & $0.31 \pm 0.05^{*}$ & $0.29 \pm 0.11$ & $0.63 \pm 0.03$ & $0.60 \pm 0.04$ \\
\hline
\end{tabular}

Values were obtained $4 \mathrm{~h}$ after one-legged knee extensions (basal) and further $4 \mathrm{~h}$ of insulin and glucose (clamp group) or saline infusion (control group). Means \pm SE, $n=6 .{ }^{*} P<0.05$ between baseline values and values obtained after insulin infusion at second clamp step (Ins ${ }_{\mathrm{II}}$ ).

adipose tissue LPL (1). The exact cause of the decrease in serum triacylglycerol is not known, but might be mediated in part by the fall in arterial FFA and thus by a decreased synthesis of triglycerides by the liver. We found, however, that the magnitude of fall in plasma VLDL-triacylglycerol concentrations during euglycemic hyperinsulinemia was not correlated to the decrease in FFA $(r=0.17)$, which is in accordance with Bazelmans et al. (28). This might suggest that insulin has a more direct effect on hepatic triacylglycerol-rich lipoprotein secretion, which was also reported in cultured rat hepatocytes in which insulin inhibited the secretion of triacylglycerols and cholesterols of VLDL, at least in the short term $(29,30)$.

As VLDL-triacylglycerol serves as substrate for m-LPL, the decrease in circulating VLDL-triacylglycerols might cause the decrease in m-LPLA. However, the insulin-induced decrease in circulating VLDL-triacylglycerol tended to be inversely associated with the decrease in m-LPLA $(r=-0.65, P>0.1)$, indicating that circulating VLDL-triacylglycerol is not directly involved in the regulation of $\mathrm{m}$-LPLA.

During insulin infusion serum-cholesterol decreased slightly but significantly due to a $16 \%$ decrease in $\mathrm{HDL}_{2}$-cholesterol, while $\mathrm{HDL}_{3}$-cholesterol remained unchanged. Since insulin at a physiological concentration decreased HDL-cholesterol while LDL-cholesterol was unchanged, a consequence of these findings in everyday life might be that in conditions with high average plasma insulin concentrations a change in the LDL-cholesterol/HDL-cholesterol ratio might be found. Actually, in the present study the LDL-cholesterol/HDL-cholesterol ratio increased significantly from 2.83 to 3.11 with insulin infusion, but was constant during saline infusion.

During the euglycemic clamp procedure we found a decrease in m-LPLA. This effect in muscle is in contrast to that seen in adipose tissue, as other clamp studies have shown a stimulatory effect of insulin on whole adipose tissue LPLA in normal subjects $(1,2)$. However, when insulin was added to primary cultures of isolated human adipocytes over a broad range of concentrations, an increase in cellular LPLA was only seen at pharmacologic concentrations $\left(400 \mathrm{ng} \cdot \mathrm{ml}^{-1} ; 31\right)$. Recently it was shown that the glucose concentration of the incubation medium is of importance for LPLA in cultured human adipocytes (24). In animal studies insulin appears to decrease m-LPLA (32) and the present results indicate a similar effect in man. Thus, our data taken together with previous results obtained in adipose tissue indicate that regulation of LPLA is tissue specific. In nonexercised muscle the effect of insulin on LPLA is closely correlated to the effect on muscle glucose uptake, and basal LPLA is a marker of muscle insulin sensitivity. Finally, the close correlation between insulin-induced in- crease in thigh glucose uptake and decrease in m-LPLA, which is thought to be due to activation of phospholipase $C$, suggests that insulin-induced increase in muscle glucose uptake in man could be due to activation of phospholipase $\mathrm{C}$.

\section{Acknowledgments}

Expert technical assistance was provided by Betina Bolmgreen.

The present study was supported by grants from the Danish Medical Research Council, The Danish Heart Foundation, Novo Research Foundation, and The Danish Diabetes Association.

\section{References}

1. Sadur, C. N., and R. H. Eckel. 1982. Insulin stimulation of adipose tissue lipoprotein lipase. J. Clin. Invest. 69:1119-1125.

2. Yki-Järvinen, H., M.-R. Taskinen, V. A. Koivisto, and E. A. Nikkilä. 1984. Response of adipose tissue lipoprotein lipase activity and serum lipoproteins to acute hyperinsulinaemia in man. Diabetologia. 27:364-369.

3. Jacobs, I., H. Lithell, and J. Karlsson. 1982. Dietary effects on glycogen and lipoprotein lipase activity in skeletal muscle in man. Acta Physiol. Scand. 115:85-90.

4. Lithell, H., B. Karlström, I. Selinus, B. Vessby, and B. Fellström. 1985. Is muscle lipoprotein lipase inactivated by ordinary amounts of dietary carbohydrates? Hum. Nutr. Clin. Nutr. 39:289-295.

5. Lithell, H., M. Cedermark, J. Fröberg, P. Tesch, and J. Karlsson. 1981. Increase of lipoprotein-lipase activity in skeletal muscle during heavy exercise: relation of epinephrine excretion. Metab. Clin. Exp. 30:1130-1134.

6. Saltiel, A. R., J. A. Fox, P. Sherline, and P. Cuatrecasas. 1986. Insulin-stimulated hydrolysis of a novel glycolipid generates modulators of cAMP phosphodiesterase. Science (Wash. DC). 233:967-972.

7. Standaert, M. L., R. V. Farese, D. R. Cooper, and R. J. Pollet. 1988. Insulin-induced glycerolipid mediators and the stimulation of glucose transport in BC3H-1 myocytes. J. Biol. Chem. 263:86968705.

8. Strålfors, P. 1988. Insulin stimulation of glucose uptake can be mediated by diacylglycerol in adipocytes. Nature (Lond.). 335:554556.

9. Chan, B. L., M. P. Lisanti, E. Rodriquez-Boulan, and A. R. Saltiel. 1988. Insulin stimulated release of lipoprotein lipase by metabolism of its phosphatidylinositol anchor. Science (Wash. DC). 241:1671-1673.

10. Andersen, P., R. P. Adams, G. Sjøgaard, A. Thorboe, and B. Saltin. 1985. Dynamic knee-extension as a model for the study of an isolated exercising muscle in humans. J. Appl. Physiol. 59:1647-1653.

11. Andersen, P., and B. Saltin. 1985. Maximal perfusion of skeletal muscle in man. J. Physiol. (Lond.). 366:233-249.

12. Richter, E. A., K. J. Mikines, H. Galbo, and B. Kiens. 1989. Effect of exercise on insulin action in human skeletal muscle. J. Appl. Physiol. 66:876-885.

13. DeFronzo, R. A., J. D. Tobin, and R. Andres. 1979. Glucose 
clamp technique: a method for quantifying insulin secretion and resistance. Am. J. Physiol. 237 (Endocrinol. Metab. Gastrointest. Physiol. 6): E214-E223.

14. Vessby, B., J. Boberg, J. B. Gustafsson, B. Karlström, H. Lithell, and A. M. Östlund-Lindquist. 1980. Reduction of high density lipoprotein cholesterol and apolipoprotein A-1 concentrations by a lipid lowering diet. Atherosclerosis. 35:21-27.

15. Shimizu, S., K. Inoue, Y. Tani, and H. Yamada. 1970. Enzymatic microdetermination of serum free fatty acids. Anal. Biochem. 98:341-345.

16. Kiens, B. 1984. Metabolisme i skeletmusklen under arbejde hos mennesket: effekten af træning. Ph.D. thesis. University of Copenhagen, Copenhagen, Denmark. 95 pp.

17. Bergmeyer, H. V. 1974. Methods of Enzymatic Analysis. H. V. Bergmeyer, editor. 2nd ed. Academic Press, New York. 2353 pp.

18. Christensen, N. J., P. Vestergaard, T. Sørensen, and O. J. Rafaelsen. 1980. Cerebrospinal fluid adrenaline and noradrenaline in depressed patients. Acta Psychiatr. Scand. 61:178-182.

19. Lithell, H., and J. Boberg. 1970. Determination of lipoproteinlipase activity in human skeletal muscle tissue. Biochim. Biophys. Acta. 528:58-68.

20. Arner, P., J. Bolinder, P. Engfeldt, and H. Lithell. 1983. The relationship between the basal lipolytic and lipoprotein lipase activities in human adipose tissue. Int. J. Obesity. 7:167-172.

21. Nilsson-Ehle, P., and H. J. Aschotz. 1976. A stable radioactive substrate emulsion for assay of lipoprotein lipase. J. Lipid Res. 17:536-541.

22. Lowry, O. H., and J. V. Passonneau. 1973. A flexible system of enzymatic analysis. Academic Press, New York.

23. Essen, B., A. Lindholm, and J. Thornton. 1980. Histochemical properties of muscle fibre types and enzyme activities in skeletal muscle of standard bred trotters of different ages. Equine Vet. J. 12:175180.
24. Kern, P. A., A. Mandic, and R. H. Eckel. 1987. Regulation of lipoprotein lipase by glucose in primary cultures of isolated human adipocytes. Diabetes. 36:1238-1245.

25. Lillioja, S., A. A. Young, C. L. Cutter, J. L. Ivy, W. G. H. Abbot, J. K. Rawadzki, H. Yki-Järvinen, L. Christin, T. W. Secomb, and C. Bogardus. 1987. Skeletal muscle capillary density and fiber type are possible determinants of in vivo insulin resistance in man. J. Clin. Invest. 80:415-424.

26. Kiens, B., and H. Lithell. 1989. Lipoprotein metabolism influenced by training-induced changes in human skeletal muscle. $J$. Clin. Invest. 83:558-564.

27. Lithell, H., K. Hellsing, G. Lundquist, and P. Malmberg. 1979. Lipoprotein-lipase activity of human skeletal muscle and adipose tissue after intensive physical exercise. Acta Physiol. Scand. 105:312315 .

28. Bazelmans, J., P. J. Nestel, and C. Nolan. 1983. Insulin-induced glucose utilization influences triglyceride metabolism. Clin. Sci. (Lond.). 64:511-516.

29. Mangiapane, E. H., and D. N. Brindley. 1986. Effects of dexamethasone and insulin on the synthesis of triacylglycerols and phosphatidylcholine and the secretion of very-low-density-lipoproteins and lysophosphatidylcholine by monolayer cultures of rat hepatocytes. Biochem. J. 233:155-160.

30. Bartlett, S. H., and G. F. Gibbons. 1988. Short- and longer-term regulation of very low-density lipoprotein secretion by insulin, dexamethasone and lipogenic substrates in cultured hepatocytes. Biochem. J. 249:37-43.

31. Kern, P. A., S. Marschall, and R. H. Eckel. 1985. Regulation of lipoprotein lipase in primary cultures of isolated human adipocytes. $J$. Clin. Invest. 75:199-208.

32. Gorski, J., and B. Stankiewicz-Choroszuba. 1982. The effect of hormones on lipoprotein lipase activity in skeletal muscles of the rat. Horm. Metab. Res. 14:189-191. 